\title{
Unexpected bowel obstruction after the treatment of gastric varices
}

\author{
Ryo Yamauchi ${ }^{1}$, Kazuhide Takata ${ }^{2}$, and Fumihito Hirai ${ }^{2}$ \\ ${ }^{1}$ Fukuoka University \\ ${ }^{2}$ Fukuoka University Faculty of Medicine
}

June 10, 2020

\begin{abstract}
As a complication of GV treatment with Histoacryl@, boweel obstruction is not common. However, when the patients with a history of abdominal surgery complain of an abdominal pain after the GV treatment, we should also consider bowel obstruction.

Unexpected bowel obstruction after the treatment of gastric varices

*Ryo Yamauchi, Kazuhide Takata, Fumihito Hirai

Department of Gastroenterology and Medicine, Fukuoka University Faculty of Medicine, Fukuoka, Japan
\end{abstract}

\section{*Corresponding author:}

Ryo Yamauchi

Department of Gastroenterology and Medicine, Fukuoka University Faculty of Medicine

7-45-1 Nanakuma, Jonan, Fukuoka 814-0180, Japan

E-mail: r_christinue2017@yahoo.co.jp

\section{Key Clinical Meeage}

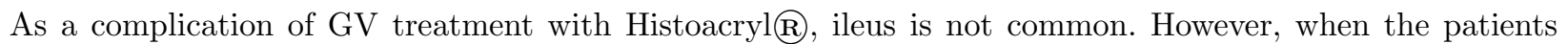
with a history of abdominal surgery complain of an abdominal pain after the GV treatment, we should also consider ileus.

\section{Question}

A 66-year-old man with decompensated alcoholic cirrhosis presented with abdominal pain. He had a history of an appendectomy 23 years previously. He underwent endoscopic injection sclerotherapy (EIS) using N-butyl2-cyanoacrylate (Histoacryl@) for gastric varices (GV) 1 month previously (Figure 1). Physical examination was normal. Abdominal X-ray revealed small intestinal gas with niveau and a 3 -cm, high-density structure in the pelvic cavity (Figure 2). What is the diagnosis and cause?

\section{Answer}

The structure was found in the GV after EIS treatment. We believe that the small intestine obstruction resulted from a part of the polymer falling out of the GV after EIS treatment. Bowel obstruction was treated conservatively and, the polymer was excreted naturally from the intestine. GV, detected using endoscopy, are found in $20 \%$ of patients with cirrhosis portal hypertension. Treatment for GV using Histoacryl@ was first reported in $1986^{1}$, and it became the first-line management option of GV due to its rapid hardening quality in the blood ${ }^{2}$. After sclerotherapy, solidified Histoacryl@ may be frequently extruded as a polymer 
into the lumen ${ }^{2}$. There are no previous reports of bowel obstruction caused by the polymer after EIS using Histoacryl@; however, it is possible that the extruded polymer caused the obstruction.

\section{Acknowledgements}

We would like to thank Editage (www.editage.jp) for English language editing.

\section{Conflict of interest statement}

None of the authors have conflicts of interest associated with this manuscript. No external funding source was utilized for this paper.

\section{Author's contributions}

Ryo Yamauchi designed the study, collected data, and drafted the manuscript.

Kazuhide Takata designed the study and collected data.

Fumihito Hirai approved the article.

All authors critically revised the manuscript, approved the final version to be published, and agree to be accountable for all aspects of the work.

\section{References}

1. Soehendra, N., Grimm, H., Nam, V.C., and Berger, B. 1987. N-butyl-2cyanoacrylate: a supplement to endoscopic sclerotherapy. Endoscopy 19: 221-224.

2. Wang, Y.M., Cheng, L.F., Li, N., Wu, K., Zhai, J.S., and Wang, Y.W. 2009. Study of glue extrusion after endoscopic N-butyl-2-cyanoacrylate injection on gastric variceal bleeding. World J Gastroenterol 15: 4945-4951.

\section{Figure Legends}

\section{Figure 1.}

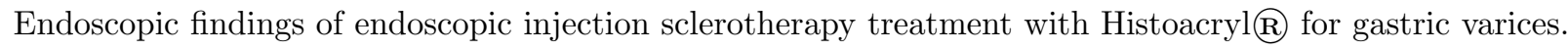

\section{Figure 2.}

Abdominal X-ray showing small intestinal gas with niveau and a $3-\mathrm{cm}$, high-density structure in the pelvic cavity. 


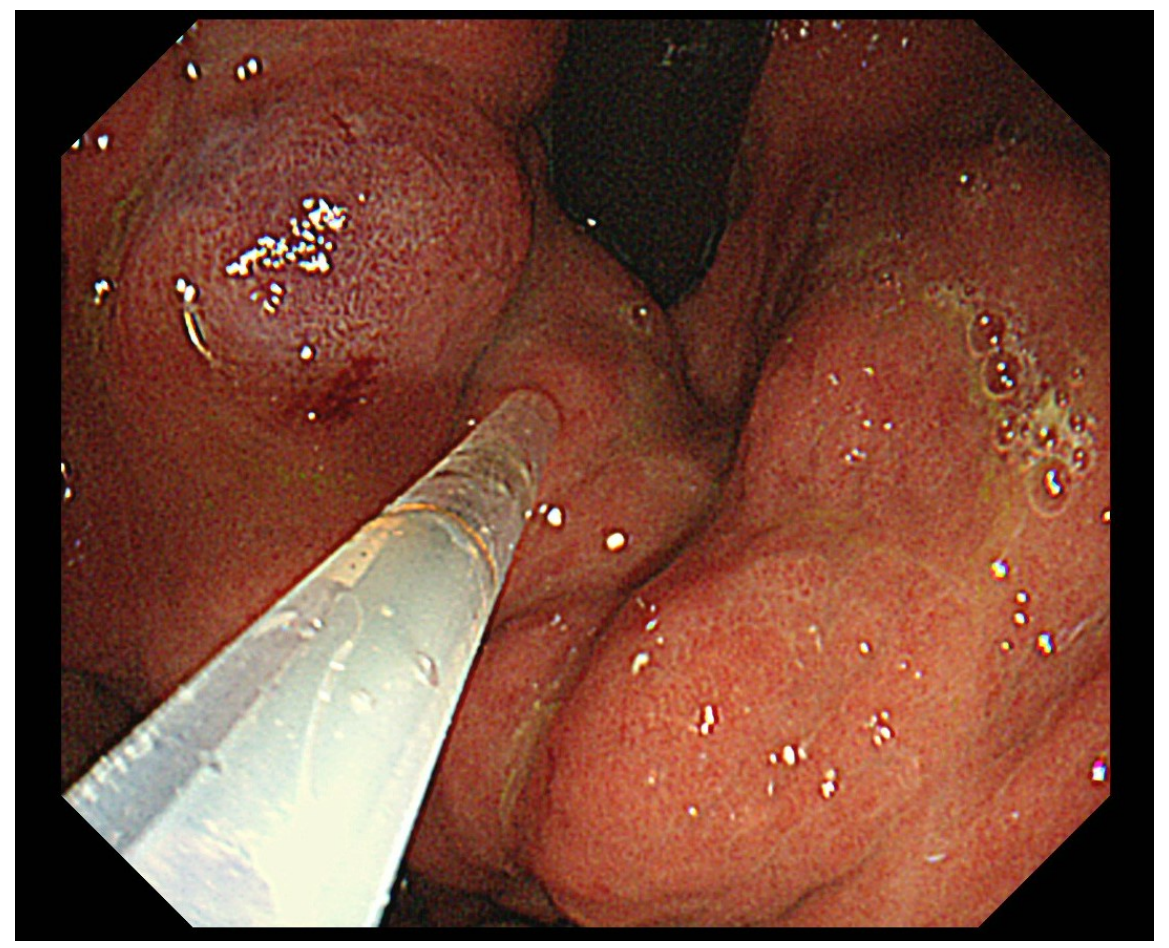




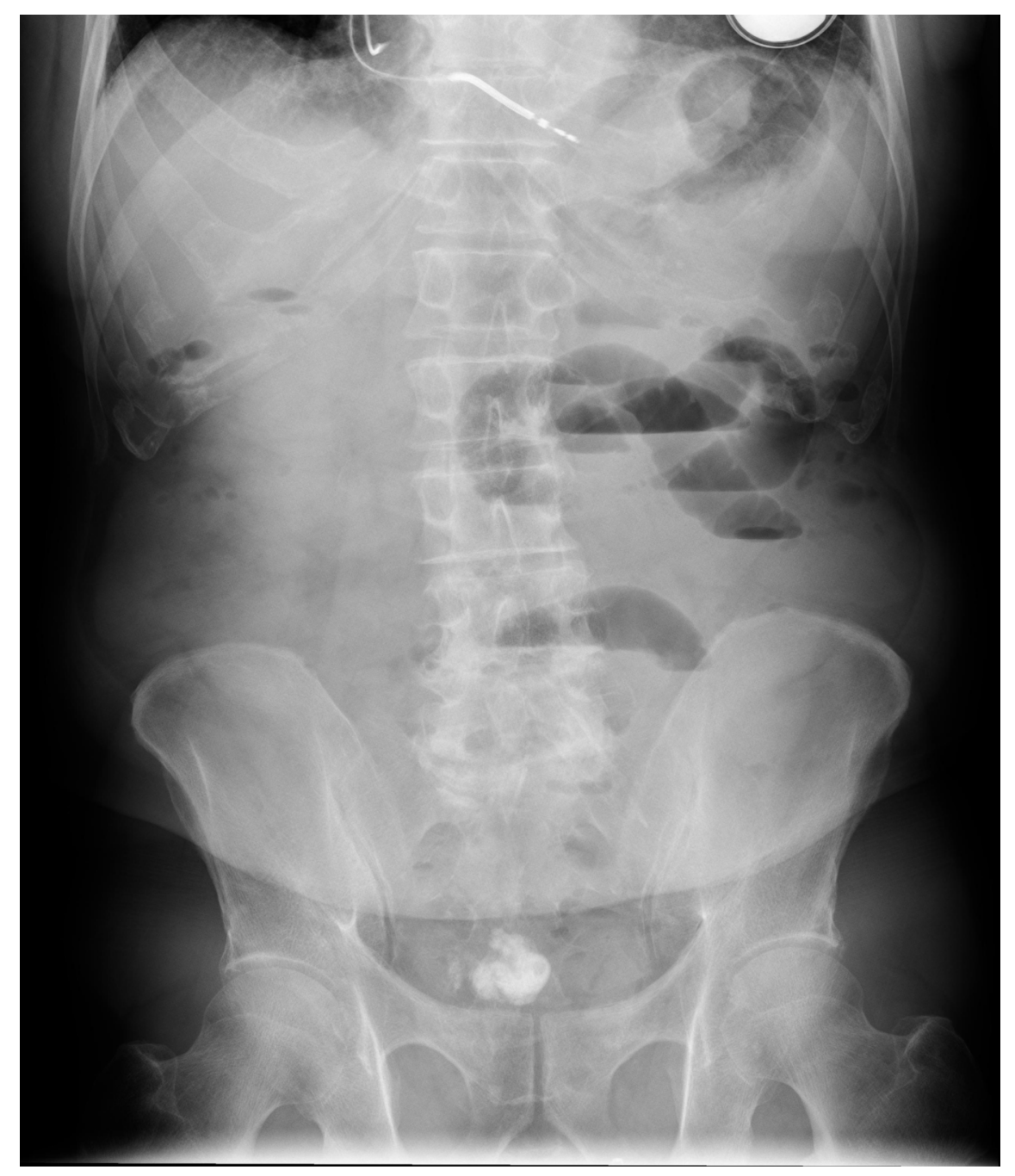

